\title{
Analysis of glycemic index, glycemic load and acceptability of enteral formulas based on tempeh flour and jicama flour as innovations for hyperglycemic patients
}

\author{
Wijayanti, L., Nuryanto, Rahadiyanti, A., Fitranti, D.Y., Dieny, F.F., Anjani, G. and \\ *Nissa, C.
}

Department of Nutrition Science, Faculty of Medicine, Universitas Diponegoro, Semarang

\begin{abstract}
Article history:
Received: 29 December 2019

Received in revised form: 25

February 2020

Accepted: 29 February 2020

Available Online: 30 May

2020
\end{abstract}

\section{Keywords:}

Hyperglycemia,

Enteral formula,

Tempeh flour,

Jicama flour,

Glycemic index,

Acceptability

\section{DOI:}

https://doi.org/10.26656/fr.2017.4(S3).S19

\begin{abstract}
Low glycemic index formula are recommended for patients with hyperglycemia. Although tempeh and jicama flour contains fiber, arginine, glycine, inulin and alpha-linolenic acid that can be used as ingredients for enteral formulas of hyperglycemic patients, the evidence in reducing the glycemic index has not been proven. This study analyzed the differences of glycemic index (GI), glycemic load (GL) and acceptability of enteral formula based on tempeh flour and jicama flour for hyperglycemic patients. An experimental study with a completely randomized single factor design, by using the three ratios of tempeh flour to jicama flour A (2:3), B (1:1) and C (5:3). The glycemic index test used a one-shot case study model on 30 women selected. Acceptability test (hedonic test) was held on 30 semi-trained panelists. Data was analyzed using the Kruskal Wallis test, Mann Whitney, and independent t-test. The GI of formulas A, B and C were 101.15, 96.21 and 41.06. The GL of three formulas were 114, 86, and 41. Panelists like the color, flavor, and texture of formulas $\mathrm{A}, \mathrm{B}$ and $\mathrm{C}$, while the taste of the formula was considered to be neutral. The results showed there were significant differences between the GI and the flavor of formulas A and C ( $=0.002),(p=0.011)$ and B and C $(p=0.013),(p=0.036)$. There were no differences between color, flavor and texture of the formulas $(p>0.005)$. There are significant differences of the GI and the acceptability in taste attributes between formulas A, B and C. Formula C has the lowest GI and GL but requires improvement of taste attribute.
\end{abstract}

\section{Introduction}

Hyperglycemia is a complication that often occurs in patients with critical conditions, both diabetic and nondiabetic patients (Godinjak et al., 2015). The number of hyperglycemia is $40 \%$ in patients with critical conditions (Farrokhi et al., 2011). When critical patients have hyperglycemia, the risk of mortality will be higher (31\%) than patients with normal blood glucose (11.3\%) (Godinjak et al., 2015).

Critical patients with hyperglycemia, especially with decreased consciousness, need nutritional support, both enteral and parenteral because of the patient's inability to receive food orally (Stroud et al., 2003; Lewis et al., 2016). Not only to meet intake needs, providing nutritional support for hyperglycemia patients must also be able to reduce the patient's blood glucose levels. The American Society for Parenteral and Enteral Nutrition (ASPEN) guidelines recommend enteral nutrition compared to parenteral in patients with good functional intestinal conditions because it can reduce infection morbidity and length of stay in hospital (Beyer, 2013; Lewis et al., 2016).

As many as $30 \%$ of patients who get the standard enteral formula continuously are reported to have hyperglycemia (Drincic et al., 2017). The standard enteral formula that is usually given to patients has low fat, low fiber and high simplex carbohydrate composition that is quickly absorbed so it causes hyperglycemia if given continuously. It is also worsened by an increase in stress mediators due to the critical condition (Gosmanov, 2013). Patient with a continuous hyperglycemia condition, trigger changes in the body that increase the risk of infection, slow wound healing, organ failure, prolonged hospitalization, and death (Farrokhi et al., 2011).

It is important to carry out glucose and lipid control for patients receiving enteral nutrition, especially longterm enteral nutrition (Farrokhi et al., 2011). The 
American Association of Clinical Endocrinologists and the American Diabetes Association (AACE/ADA) recommend a blood glucose target of 140 to $180 \mathrm{mg} / \mathrm{dL}$ in critical patients. One of them is by giving the enteral formula with monounsaturated fatty acids (MUFA) and low glycemic index (Hofman et al., 2006; Beyer, 2013). Low glycemic index in food is influenced by several factors, including the type of carbohydrates contained in foods, fructose and lactose, the lack of food process, amylose levels higher than amylopectin levels, high levels of fiber, fat, and protein. The glycemic index also influences the glycemic load which determines the number of enteral formulas that can be given to hyperglycemic patients (Gattas et al., 2007).

In order to maintain the stability of blood glucose levels, enteral formulas can be made by ingredients such as tempeh flour, jicama flour, skim milk, and soybean oil (Aluko, 2012; Pei et al., 2017; Wu et al., 2017). Three enteral formulas using tempeh flour and jicama flour were calculated priorly to get the best compositions according to ASPEN guideline.(Gosmanov, 2013; Paris et al., 2017). Different addition of jicama flour and tempeh flour, nutritional content, and sensory characteristics can affect the glycemic index, glycemic load, and enteral formula acceptability (Eke-Ejiofor et al., 2015; Yulianti and Sholichah, 2019). Therefore, this study was aimed to compare glycemix index, glycemic load, and acceptability on three enteral formulas.

\section{Materials and methods}

This study was an experimental research with a completely randomized design one factor, enteral formula with the ratio of tempeh flour to jicama flour A (2:3), B (1:1) and C (5:3). This study was part of the main research entitled "Development of a Powder-Based Enteral Formula for Patients with Hyperglycemia". This research was conducted in four stages, preliminary research, preparation, implementation, and data analysis. Preparation and determination of enteral formulas were carried out at the preliminary research stage. The formula that was made and selected has met the requirements of the enteral formula for hyperglycemia patients, both in terms of nutrient composition and energy density (Gosmanov, 2013). In the preparation stage, tempeh flour and jicama flour were prepared using the oven method as an enteral formula. The implementation phase of the research was the glycemic index test and the acceptability test on the three enteral formulas.

The glycemic index test was using a one-shot case study design, by giving the deliberate treatment to the subject of the reference food (white bread) and enteral formula formulation then measuring blood glucose after the treatment (Brouns and Bjrock, 2017). A total of $56 \mathrm{~g}$ of white bread containing 25-gram available carbohydrate was calculated based on the nutritional value information printed on the label on the package, while the number of enteral formulas given is calculated based on the proximate test results. The glycemic index test was performed on 30 female subjects aged 20-30 years with inclusion criteria in a healthy condition, normal body mass index $\left(18.5-22.9 \mathrm{~kg} / \mathrm{m}^{2}\right)$, normal fasting blood glucose levels $(70-100 \mathrm{mg} / \mathrm{dL})$, do not have a family with a history of diabetes mellitus, do not smoke, do not consume alcohol, are not pregnant and fill out informed consent to express willingness to be the subject of research.

The subjects were taken by a consecutive sampling method. The subjects were then divided into 3 groups randomly (Groups A, B, and C) to determine the formula to be given. All groups (A, B, and C) consumed reference foods (white bread), Group A consumed enteral formula A, Group B consumed enteral formula B and Group $\mathrm{C}$ consumed enteral formula $\mathrm{C}$.

The day before treatment the subject was required to fast (except water) for 10 hours starting from 22:00 until 08.00 the next morning. Then subjects were asked to consume test foods (white bread and enteral formulas). Blood samples were taken every 30 mins after consuming test foods for $2 \mathrm{hrs}$. Each treatment was given a distance of 3 days to avoid bias. The GI test was performed using the glucose test kit Gluco Dr. AGM 2100. The yield data was then spread with time as the Xaxis and blood glucose levels as the Y-axis. The GI was calculated by comparing the area under the test food curve and standard food, then the results were averaged (Brouns and Bjrock, 2005).

Then the acceptance test was using a hedonic test which assessed by 30 rather trained panelists of the Nutrition Science Student Undip. The food quality attributes tested were color, flavor, taste, and texture on all three formulations. The assessment of the quality attributes of enteral formulas uses 5 likeness scales, i.e. (very dislike), 2 (dislike), 3 (neutral), 4 (like), and 5 (very like) (Lim, 2011).

\section{Results}

\subsection{Enteral formula samples}

Table 1 shows the results of the preliminary research in the form of the determination and selection of enteral formula samples. Enteral formulas used as samples were selected based on meeting the requirements of enteral formulas for hyperglycemia patients. 
Table 1. Comparison of each enteral formula sample based on jicama flour and tempeh flour

\begin{tabular}{lccc}
\hline \multicolumn{1}{c}{ Composition } & A (2:3) & B (1:1) & C (5:3) \\
\hline Tempeh flour (g) & 60 & 60 & 70 \\
Jicama flour (g) & 90 & 60 & 42 \\
Skim milk (g) & 50 & 50 & 50 \\
Soybean Oil (g) & 15 & 15 & 15 \\
Refined sugar (g) & 13 & 13 & 13 \\
Maltodextrin (g) & 50 & 50 & 50 \\
\hline
\end{tabular}

Composition for $1000 \mathrm{~mL}$ formula

\subsection{Glycemic index test}

\subsubsection{Subject characteristics}

The subjects in this study were thirty women. The characteristics of the subjects of this study can be seen in Table 2.

Table 2. Characteristics of research respondents

\begin{tabular}{lc}
\hline \multicolumn{1}{c}{ Characteristics } & Mean \pm SD \\
\hline Age $($ years $)$ & $21.20 \pm 0.139$ \\
Height $(\mathrm{cm})$ & $157.07 \pm 0.969$ \\
Weight $(\mathrm{kg})$ & $50.95 \pm 0.782$ \\
BMI $\left(\mathrm{kg} / \mathrm{m}^{2}\right)$ & $20.64 \pm 0.191$ \\
GDP $(\mathrm{mg} / \mathrm{dl})$ & $84.27 \pm 0.97$ \\
\hline
\end{tabular}

Value represents Mean $\pm \mathrm{SD}(\mathrm{n}=30)$

\subsubsection{Response to increase in blood glucose value}

The average results of examining blood glucose every 30 mins for $2 \mathrm{hrs}$ after reference food and 3 types of enteral formulas can be seen in Table 3, Table 4 and Table 5 .

\subsubsection{Group A}

Table 3 shows the fluctuations in the average blood glucose level of the test group A subjects after consuming the reference food and enteral formula A. Based on Table 3 it can be seen that the blood glucose value of the subjects after consuming reference foods increased until the 60th minute and then decrease steadily, while the blood glucose of the subjects after consuming enteral formula A B reached its peak in the 30th minute and gradually decreased. There was a significant difference between blood glucose after consuming reference foods and enteral $\mathrm{B}$ formula at the 90th and 120th mins $(p=0.040)$ and $(p=0.012)$.

\subsubsection{Group B}

Table 4 shows the fluctuations in the average blood glucose level of the test group B subjects after consuming the reference food and enteral B formula. Based on Table 4 it can be seen that the blood glucose value of the subjects after consuming reference foods increased in the 60th minute and then decrease steadily, while the blood glucose of the subjects after taking enteral B reached its peak in the 30th minute. There was a significant difference between blood glucose after consuming reference foods and enteral $\mathrm{B}$ formula at 90 $\operatorname{mins}(\mathrm{p}=0.023)$.

Table 3. Value of blood glucose concentration $(\mathrm{mg} / \mathrm{dL})$ at time intervals of test Group A

\begin{tabular}{lccc}
\hline & Food Reference & Formula A & $\mathrm{p}$ \\
\hline $0 \mathrm{~min}$ & $87.60 \pm 2.04$ & $83.70 \pm 2.33$ & 0.226 \\
$30^{\text {th }}$ minute & $110.60 \pm 2.69$ & $107.80 \pm 3.05$ & 0.501 \\
$60^{\text {th }}$ minute & $116.3 \pm 4.61$ & $107.70 \pm 4.07$ & 0.118 \\
$90^{\text {th }}$ minute & $108.70 \pm 3.03$ & $99.70 \pm 2.71$ & $0.040^{*}$ \\
$120^{\text {th }}$ minute & $99.90 \pm 2.71$ & $89.90 \pm 2.27$ & $0.012^{*}$ \\
\hline
\end{tabular}

Values represent Mean $\pm \mathrm{SD}(\mathrm{n}=10)$, * significant with Independent T-Test

Table 4. Value of blood glucose concentration $(\mathrm{mg} / \mathrm{dL})$ at time intervals of test Group B

\begin{tabular}{lccc}
\hline & Food Reference & Formula B & $\mathrm{p}$ \\
\hline 0 min & $84.50(76-95)$ & $85.0(81-90)$ & 0.912 \\
$30^{\text {th }}$ minute & $109.50(95-123)$ & $123.00(96-144)$ & 0.052 \\
$60^{\text {th }}$ minute & $114.00(100-137)$ & $109.50(84-129)$ & 0.143 \\
$90^{\text {th }}$ minute & $108.50(90-125)$ & $94.5(87-124)$ & $0.023^{*}$ \\
$120^{\text {th }}$ minute & $92.50(85-112)$ & $91.00(84-107)$ & 0971 \\
\hline
\end{tabular}

Values represent Median (Min-Max) $(\mathrm{n}=10)$, * significant with the Mann-Withney test

\subsubsection{Group C}

Table 5 shows the fluctuations in the average blood glucose level of the $\mathrm{C}$ test group subjects after consuming the reference food and enteral $\mathrm{C}$ formula. Based on Table 5 it can be seen that the blood glucose value of the subjects after consuming the reference food increased until the 60th minute and then decrease steadily, while the blood glucose of the subjects after consuming enteral $\mathrm{C}$ formula reached its peak in the 30th minute. There is no difference between blood glucose after consuming reference foods and enteral $\mathrm{C}$ formula.

Table 5. Value of blood glucose concentration $(\mathrm{mg} / \mathrm{dL})$ at time intervals of test Group C

\begin{tabular}{lccc}
\hline & Food Reference & Formula C & $\mathrm{p}$ \\
\hline $0 \mathrm{~min}$ & $81.70 \pm 3.98$ & $88.40 \pm 2.16$ & 0.162 \\
$30^{\text {th }}$ minute & $11510 \pm 5.17$ & $102.40 \pm 3.67$ & 0.064 \\
$60^{\text {th }}$ minute & $11630 \pm 7.71$ & $101.00 \pm 3.91$ & 0.100 \\
$90^{\text {th }}$ minute & $99.70 \pm 5.24$ & $94.10 \pm 2.58$ & 0.355 \\
$120^{\text {th }}$ minute & $85.80 \pm 2.03$ & $88.30 \pm 1.98$ & 0.392 \\
\hline
\end{tabular}

Values represent Mean $\pm \mathrm{SD}(\mathrm{n}=10)$, * significant with Independent T-Test

\subsubsection{Glycemic index and glycemic load of enteral formula}

The calculation of the area under the curve is using 
Table 6. Glycemic index categories 3 types of enteral formulas

\begin{tabular}{cccccc}
\hline Formula & Available CHO $(\mathrm{g})$ & Number of servings $(\mathrm{mL})$ & Glycemic index & GI Category & $\mathrm{p}^{*}$ \\
\hline A $(2: 3)$ & 25 & 220 & $101.15^{\mathrm{a}}$ & High & \\
B $(1: 1)$ & 25 & 277 & $96.56^{\mathrm{a}}$ & High & 0.005 \\
C $(5: 3)$ & 25 & 245 & $41.06^{\mathrm{b}}$ & Low & \\
\hline
\end{tabular}

Table 7. Glycemic load categories 3 types of enteral formulas

\begin{tabular}{cccccc}
\hline Formula & Number of servings (mL) & Available CHO (\%) & Available CHO/servings (g) & Glycemic Load & GL Category \\
\hline A $(1: 1)$ & 220 & 36.43 & 90.37 & 114.86 & High \\
B $(2: 3)$ & 277 & 40.90 & 113.72 & 86.75 & High \\
C (5:3) & 245 & 42.56 & 102.14 & 41.87 & High \\
\hline
\end{tabular}

the trapezoid method. The average results of the glycemic index values of the three enteral formulas can be seen in Table 6 . The GL describes blood glucose enhancement based on carbohydrate content contained in one serving of food. Glycemic load is calculated by multiplying the grams of available carbohydrate in the food by the food's glycemic index and then dividing by 100. The results of the glycemic load values of the three enteral formulas can be seen in Table 7.

\subsection{Acceptability test}

The results of the analysis of the acceptability of color, flavor, taste and texture of the enteral formula can be seen in Table 8. Based on Table 8, the results show there are no differences in the attributes of colors, flavors, and textures between formulas A, B, and C. Panelists gave the same color assessment, a slightly brownish yellow color, according to them the colors of the three enteral formulas were acceptable, quite bright, good and interesting, but there are a few panelists consider that the color of the three enteral formulas is rather dark but still acceptable. Most panelists liked the flavor of the three enteral formulas tested because they smelled good like soy milk and the sweet flavor of cow's milk, but some panelists thought the formula's flavor was still unpleasant.

The assessment of taste attributes found a significant difference between formulas A, B, and C. Panelists liked the taste of formulas A and B because they had a delicious, sweet and soy-like taste, while panelists were less able to accept the taste of formula $\mathrm{C}$ because of its less sweet taste and had a bitter after taste. Most panelists also considered the texture of the three enteral formulas tested to be almost similar to the texture of commercial enteral formulas, in this case, the viscosity level was good and felt soft, but there were some panelists who did not like the texture of enteral $\mathrm{C}$ formula because of the slightly rough texture like sand.

\section{Discussion}

\subsection{Glycemic index (IG)}

Both formulas A and B had high GI category (IG> 70) 101.15 and 96.36, while formula $C$ had low GI category (GI <55) with a value of 41.06 (Lisa, 2013). Statistic test showed a significant difference between formulas $\mathrm{A}$ and $\mathrm{B}$ with formula $\mathrm{C}(\mathrm{p}<0.05)$. The number of reference foods and enteral formulas given to subjects is equivalent to $25 \mathrm{~g}$ of available carbohydrates calculated by reducing total carbohydrates with food fiber. The selection of the number of available carbohydrates is to anticipate the amount of enteral formula that is too large when given to subjects. The reference food given is white bread, the selection of white bread rather than pure glucose because bread is a general food, thus making it possible to determine GI in a more physiological way (Brouns and Bjrock, 2005).

A faster glycemic response occurs in subjects who take the formula than the reference food. Glycemic response is a condition in which a person's blood sugar condition has increased or decreased when consuming food for a certain period (Venn and Green, 2007). All three groups consuming reference food in the form of white bread experienced a peak increase in blood glucose in the 60th minute, while after consuming enteral formula the peak of the increase occurred in the 30th minute as can be seen in Figure 1, Figure 2 and Figure 3. This can occur because of differences in the size of the reference food particles and the three enteral formulas. Enteral formula made from flour-shaped ingredients

Table 8 . Acceptability of three enteral formulas

\begin{tabular}{|c|c|c|c|c|c|c|c|}
\hline & Formula $\mathrm{A}$ & & Formula B & & Formula C & & $n *$ \\
\hline & Median (Min-Max) & & Median (Min-Max) & & Median (Min-Max) & & $p$ \\
\hline Color & $4(2-5)$ & Like & $4(1-5)$ & Like & $4(1-5)$ & Like & 0.887 \\
\hline Flavor & $4(2-5)$ & Like & $4(1-5)$ & Like & $3(1-5)$ & Neutral & 0.995 \\
\hline Taste & $3(1-4)^{a}$ & Neutral & $3(1-5)^{a}$ & Neutral & $3(1-4)^{b}$ & Neutral & 0.025 \\
\hline Texture & $4(2-5)$ & Like & $4(1-5)$ & Like & $3(1-5)$ & Neutral & 0.233 \\
\hline
\end{tabular}


without further processing has a smaller particle size, so the total surface area of food is getting bigger. The large total surface area of food results in food being easily degraded by digestive enzymes and increasing blood glucose faster (Venn and Green, 2007).

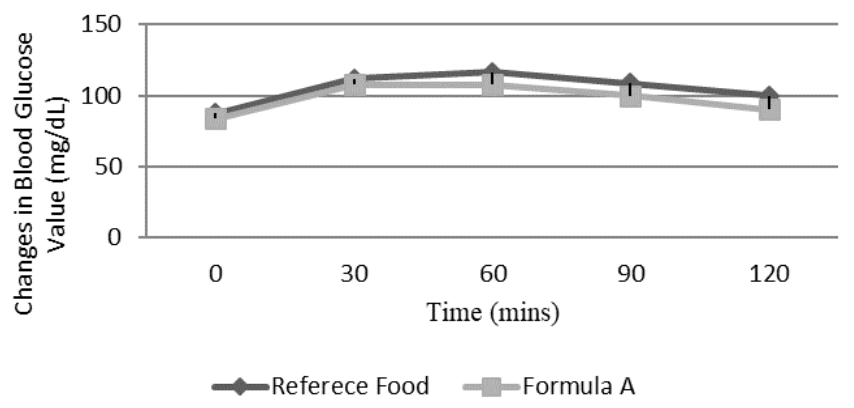

Figure 1. Increase in blood glucose of group A subject

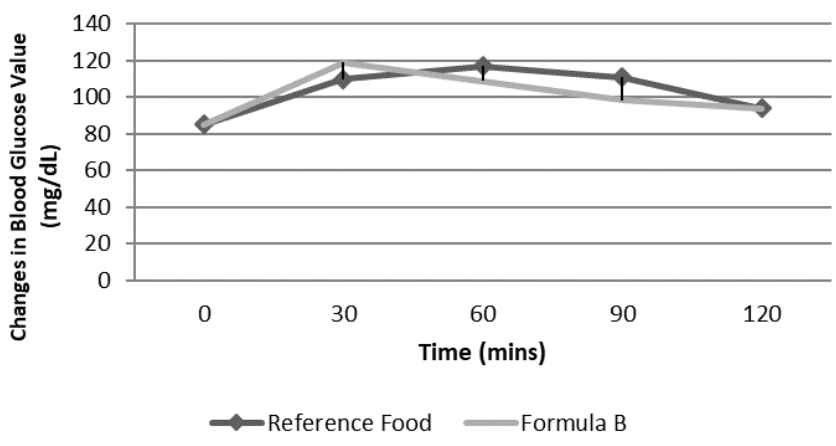

Figure 2. Increase in blood glucose of group B subject

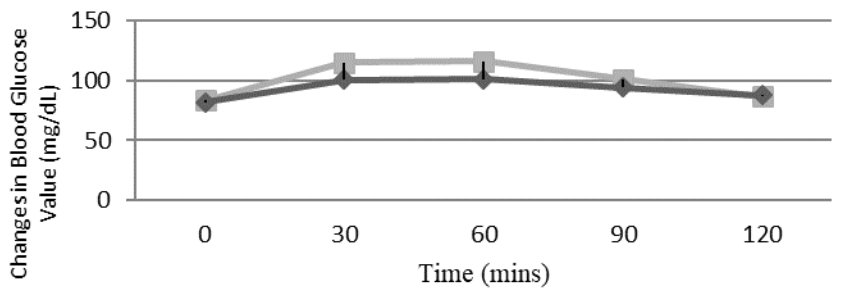

- Reference Food $\_$Formula C

Figure 3. Increase in blood glucose of group C subject

The variations of glycemic index between the three enteral formulas due to differences in extreme glycemic responses in study respondents. An increase in blood glucose that is too high occurs in $50 \%$ of respondents who are fed the enteral test formula A and B. High blood glucose response results in the calculation of the area under the curve to be greater, so the GI becomes high (Venn and Green, 2007). Each individual has a unique and varied glycemic response to foods containing carbohydrates (Whelan et al., 2010). The difference in response to a person's blood rise after consuming food is influenced by many factors such as genetic, epigenetic, physiological and metabolic factors (Morris et al., 2013). The researchers only included respondents with families without a history of diabetes mellitus to avoid bias due to genetic factors. A high level of respondent activity the day before the test can also affect blood glucose uptake in the muscles. Based on the interview results of the subject's physical activity the day before the test, it was found that the level of subject activity was mild. High carbohydrate and fat food intake the day before the test can also have an impact on poor glucose tolerance, resulting in a drastic increase in blood glucose. Therefore, the day before the test, respondents are asked to fast for at least 10 hours to prevent a rise in blood glucose that is drastic (Brouns and Bjrock, 2005).

The high glycemic index in formulas A and B is also influenced by several things, such as fiber content, amylose and amylopectin, and starch digestibility. Formula $\mathrm{A}$ and $\mathrm{B}$ contain higher fiber than formula $\mathrm{C}$ which is $17.57 \mathrm{~g}$ and $12.38 \mathrm{~g}$ per serving based on proximate test results, but formulas A and B also contain more jicama flour where jicama flour has higher amylopectin content $(82.6 \%)$ compared to the levels of amylose (18.4\%) (Stevenson et al., 2007).

The results showed that food which had a higher proportion of amylopectin compared to amylose had a higher GI value as well. Amylopectin has the property to be more easily digested (hydrolyzed) by digestive enzymes than amylose so that the process of breaking down into simple sugars occurs more quickly (Whelan et al., 2010; Dipnaik and Kokare, 2017). As a result, glucose absorption in the intestine occurs quickly and respondent's blood glucose levels rise rapidly.

Formula enteral $\mathrm{A}$ and $\mathrm{B}$ contain more jicama flour than formula $\mathrm{C}$ where jicama contains $21 \%$ starch which tends to gelatinize at $53-63^{\circ} \mathrm{C}$ (Buckman et al., 2018). This gelatinization process can also affect the glycemic index levels of the three enteral formulas. Gelatinized starch will be more easily hydrolyzed by digestive enzymes (alpha-amylase) to glucose so that the increase in blood glucose levels takes place more quickly (Russell et al., 2016).

\subsection{Acceptance (Hedonic test)}

\subsubsection{Color}

Based on the hedonic test, the panelist like the colors of the three enteral formulas and based on the statistical analysis there was a no different color in the three formulas. This is based on the panelist description that all formulas have the same color, which is yellowishbrown. The brownish color of enteral formula comes from jicama and tempeh which had a browning reaction when drying.

Browning reactions (Maillard) in jicama and tempeh occur because of the reaction between reducing sugars from carbohydrates with the primary amino group of jicama and tempeh proteins (Tamanna and Mahmood, 2015). The Maillard reactions can occur at $37^{\circ} \mathrm{C}$ and are faster at $100^{\circ} \mathrm{C}$. The tempehrature used in the 
manufacture of jicama flour and tempeh flour is $65^{\circ} \mathrm{C}$ and $60^{\circ} \mathrm{C}$ to enable the Maillard (Reyes-Bastidas et al., 2010). Also, during the drying process the sugar contained in the jicama is in contact with heat and had a browning reaction. The tempeh and jicama flour have almost the same color, but tempeh flour has a slightly darker color than jicama flour. Tempeh flour contains high amino acid lysine $(104.3 \mathrm{mg} / \mathrm{g})$, where lysine contains two amen groups so that it is more reactive to reducing sugars and produce a darker brown color (Yulianti and Sholichah, 2019)

\subsubsection{Flavor}

Based on the hedonic test results obtained the level of acceptance flavor of the enteral formula is neutral and like, while the results of statistical analysis showed no difference in flavor of the enteral formula. Panelists liked the flavor of formulas A and B because it smelled like the soy milk flavor, but some panelists thought the flavor of formula $\mathrm{C}$ was still unpleasant. There is no difference in flavor between the three enteral formulas because all have a soy dominant flavor.

There are 26 active flavor components in soybeans contribute to the creation of a distinctive flavor of soybeans, where 8 of the 26 active components cause an unpleasant scent (Lv et al., 2011). The presence of the enzyme lipoxygenase in soybean hydrolyzes soybean fat and produces volatile compounds such as hexanol, hexanal, and 2-pentyl furan also plays a role in the appearance of unpleasant scent (Vara-ubol et al., 2003).

Hot water blanching at a tempehrature of $100^{\circ} \mathrm{C}$ for 10 mins is one of the methods have been made to reduce the unpleasant flavor of tempeh. The process of hot water blanching by using water with a tempehrature of more than $80^{\circ} \mathrm{C}$ for 2 to 10 mins in making tempeh flour and jicama can inactivate the lipoxygenase enzyme and reduce the unpleasant smell in the flour produced. However, in the blanching process within 10 mins only able to reduce 5 of the 8 active components in soybeans, so the unpleasant flavor cannot be completely removed (Lv et al., 2011).

The unpleasant flavor of tempeh can be minimized by making modifications to the process of making tempeh. Modifications made are by using a mixture of the culture of Rhizopus oligosporus and Saccharomyces cerevisiae in the fermentation process (Kustyawati et al., 2017). Another method to minimize unpleasant scent is by heating treatment. The making of tempeh flour by heating treatment in the form of steaming for 25 mins then roasting for 20 mins before drying, obtained the results of an attractive flavor and organoleptic tests favored by the panelists (Yulianti and Sholichah, 2019)

\subsubsection{Taste}

Panelists gave a neutral assessment for the taste attributes of the three enteral formulas, while based on statistical analysis there were significant taste differences between the three enteral formulas. The panelists described formulas A and B as having a good, sweet taste and resembling soy milk. Formula $\mathrm{C}$ is described as having a less sweet taste and there is an after taste of a bitter taste.

This is consistent with studies that have been done before, that the presence of soybeans, soy protein isolates or concentrates in tempeh in the product is described as beany, bitter, chalky, and astringent. The bitter after-taste that arises in the enteral formula in this study is influenced by the addition of tempeh flour, where tempeh contains soyasaponin and sapogenin which are the main glycoside compounds that cause a bitter taste in soybeans (Lv et al., 2011). Also, soybeans contain isoflavones which can cause a bitter taste in soybean processed products, but the levels of isoflavones in tempeh are lower than soybeans because of the many processing processes in tempeh. There are around $24 \%$ of isoflavones that are still present in tempeh, therefore the processed products of tempeh may still taste bitter (Kustyawati et al., 2017). Tempeh flour also contains amino acid lysine which is an amino acid that has the most bitter taste compared to other amino acids that cause bitter taste.

Formula A and B have no difference in taste because of the composition of tempeh flour and jicama which is not too much different. Formula A and B tend to have a sweeter taste. The sweet taste comes from jicama flour and sugar added. The amount of sugar contained in all formulas is the same, more sweetness in formulas A and B occurs because of the addition of more jicama flour (19.7 $\mathrm{g}$ and $16.6 \mathrm{~g}$ ). Jicama contains inulin which is a component that can give sweetness $10 \%$ lower than sugar. The role of inulin in giving sweetness is almost the same as sugar, giving sweetness without after taste because it contains a short chain oligofructose molecule (Saeed et al., 2015).

\subsubsection{Texture}

The value that often arises from the hedonic quality test of enteral formulas A, B according to the texture attribute is 4 (likes), while Formula $\mathrm{C}$ is 3 (neutral). Based on statistical analysis there were no differences between the three formulas $(p>0.05)$. Panelists considered formula A and B to have a soft but rather thick texture, while formula $\mathrm{C}$ had a slightly grained texture, but the panelists liked the level of thickness.

The texture is rather rough in formula $\mathrm{C}$ due to the 
high content of tempeh flour compared to the other two formulas. Efforts to minimize tempeh flour particles have been carried out by sifting using 80 mesh sieve to produce a fine flour particle size of $0.177 \mathrm{~mm}$. Particle size affects the level of solubility of flour, where the smaller the particle size will increase the level of solubility of a product (Sun and Zhai, 2012). However, tempeh flour contains water-insoluble fractions which make it have a low solubility despite having a fine flour size (Reyes-Bastidas et al., 2010). In addition, the solubility of flour tempeh in water is in the range of $11.3 \%$ to $23.2 \%$, where the solubility level of tempeh flour is affected by blanching treatment, tempehrature and drying time. The longer blanching treatment and drying time, as well as the higher drying tempehrature, will reduce the level of solubility of tempeh flour. The drying method using an oven is also less able to increase the solubility of tempeh flour when compared with the freeze-drying method which can increase the solubility of tempeh flour by up to $80 \%$. However, drying using the freeze-drying method requires a relatively more expensive cost, so researchers prefer the oven as a drying method (Ciurzynska and Lenart, 20111).

\section{Conclusion}

Formula $\mathrm{C}$ showed the best glycemic index and glycemic load among all formulas. Furthermore, the panelists liked all the formula colors, flavors, and textures. However, the acceptance of formula $\mathrm{C}$ taste was lower than the other two.

\section{Conflict of interest}

The authors declare that there is no conflict of interests regarding the publication of this paper.

\section{Acknowledgments}

This enteral formula based on tempeh flour and jicama flour research is granted by Diponegoro University through Development and Application Research program in the 2018 fiscal year. The author would like to thank all those who have helped this research to be resolved properly.

\section{References}

Aluko, R.E. (2012). Functional Foods and Nutraceuticals. New York: Springer Science Business Media. https://doi.org/10.1007/978-1-46143480-1

Beyer, P.L. (2013). Complications of enteral nutrition. Principles of Nutrition Support, 17, 223.

Brouns, F. and Bjrock, I. (2005). Glycemic Index Methodology. Nutrition Research Reviews, 18, 145-
171. https://doi.org/10.1079/NRR2005100

Buckman, E.S., Oduro I, Plahar, W.A., Tortoe, C. (2018). Determination ofthe chemical and functional properties of yam bean (Pachyrhizus erosus (L) Urban) flour for food system. Food Science and Nutrition, 6, 457-463. https://doi.org/10.1002/ fsn3.574.

Ciurzynska, A. and Lenart, A. (2011). Freeze-Drying Application in Food Processing and Biotechnology A Review. Polish Journal of Food and Nutrition Sciences, 61(3), 165-171. https://doi.org/10.2478/ v10222-011-0017-5

Dipnaik, K. and Kokare, P. (2017). Ratio of Amylose and Amylopectin as indicators of glycaemic index and in vitro enzymatic hydrolysis of starches of long, medium and short grain rice. International Journal of Research in Medical Science, 5(10), 4502-4505. https://doi.org/10.18203/2320-6012.ijrms20174585

Drincic, A.T., Knezevich, J.T. and Akkireddy, P. (2017). Nutrition and Hyperglycemia Management in the Inpatient Setting (Meals on Demand, Parenteral, or Enteral Nutrition). Current Diabetes Reports, 17, 59. https://doi.org/10.1007/s11892-017-0882-3

Eke-Ejiofor, J., Deedam, N. and Beleya, A. (2015). Effect of Addition of Three Leaf Jicama Flour on Dough Properties and Sensory Qualities of Bread. Journal of Food Research, 4, 133-134. https:// doi.org/10.5539/jfr.v4n6p133

Farrokhi, F., Smiley, D. and Umpierrez, G.E. (2011). Glycemic Control in Non-Diabetic Critically Ill Patients. Best Practice and Research: Clinical Endocrinology and Metabolism, 25(5), 813-824. https://doi.org/10.1016/j.beem.2011.05.004

Gattas, V., Barrera, G., Leiva, 1., Maza, M.P.D.L., Bunout, D., Steenhout, P., Klassen, P., Voss, T. and Hirsch, S. (2007). Glycemic and Insulin Indices of Tube Feeding Formulas in Healthy Adults. Revista Medica de Chile, 135(7), 879-884. https:// doi.org/10.4067/S0034-98872007000700008

Godinjak, A., Iglica, A., Burekovic, A., Jusufovic, S., Ajanovic, A., Tancica, I. and Kukuljac, A. (2015). Hyperglycemia in Critically Ill Patients: Management and Prognosis. Medical Archives, 69 (3), 157-160. https://doi.org/10.5455/ medarh.2015.69.157-160

Gosmanov, A.R. (2013). Management of Hyperglycemia During Enteral and Parenteral Nutrition Therapy. National Institute of Health, 13(1), 155-162. https:// doi.org/10.1007/s11892-012-0335-y

Hofman, Z., De Van Drunen, J. and Kuipers, H. (2006). The Glycemic Index of Standard and DiabetesSpecific Enteral Formula. Asia Pacific Jurnal Clinical Nutrition, 15(3), 412-417.

Kustyawati, Nawansih, O. and Nurdjannah, S. (2017). 
Profile of Aroma Compounds and Acceptability of Modified Tempeh. International Food Research Journal, 24(2), 734-740.

Lewis, S.R., Butler, A.R., Alderson, P. and Smith, A.F. (2016). Enteral versus parenteral nutrition for adults in the intensive care unit. Cochrane Database of Systematic Reviews, 2016(7). CD012276. https:// doi.org/10.1002/14651858.CD012276

Lim, J. (2011). Hedonic Scaling: A Review of Methods and Theory. Food Quality and Preference, 22, 733747. https://doi.org/10.1016/j.foodqual.2011.05.008

Lisa, B. (2013). Glycemic Index Food Guide. Canada: Canadian Diabetes Association. Retrieved from www.diabetes.ca/mealplanning

Lv, Y., Song, H., Li, X., Wu, L. and Guo, S. (2011). Influence of Blanching and Grinding Process with Hot Water on Beany and Non-Beany Flavor in Soymilk. Journal of Food Science, 76(1), 20-25. https://doi.org/10.1111/j.1750-3841.2010.01947.x

Morris, C., Grada, C.O., Ryan, M., Roche, H.M., Gibney, M. J., Gibney, E.R. and Brennan, L. (2013). Identification of Differential Responses to an Oral Glucose Tolerance Test in Healthy Adults. PLoS One, $\quad 8(8), \quad 1-9 . \quad$ https://doi.org/10.1371/ journal.pone. 0072890

Paris, A.S., Hernandez, J.A., Ballesteros-Pomar, M.D., Botella-Romero, F., Leon-Sanz, M. Martin-Palmero, A., Olmos, M.A.M. and Olveira, G. (2017). Evidence-Based Recommendations and Expert Consensus on Enteral Nutrition in The Adult Patient with Diabetes Mellitus or Hyperglycemia. Nutrition Journal, 41, 58-67. https://doi.org/10.1016/ j.nut.2017.02.014

Pei, X., Xie, Z., Wang, J., Shi, K., Han, F., Li, A. and Liu, H. (2017). The Effect of Various Intake Levels of Soybean Oil on Blood Glucose and Inflammation in Mice. Food and Agricultural Immunology, 29(1), 511-523. doi.org/10.1080/09540105.2017.1409194

Reyes-Bastidas, M., Reyes-Fernandez, E.Z., LopezCervantes, L., Milan-Carrillo, J., Loarca-Pina, G.F. and Reyes-Moreno, C. (2010). Physicochemical, Nutritional and Antioxidant Properties of Tempeh Flour from Common Bean (Phaseolus vulgaris L.). Food Science and Technology International, 16(5), 427-434. https://doi.org/10.1177/1082013210367559

Russell, W.R., Baka, A., Björck, I., Delzenne, N., Gao, D., Griffiths, H.R., Hadjiulucas, E., Juvonen, K., Lahtinen, S., Lansink, M., Loon, L.V., Mykkanen, H., Ostman, E., Riccardi, G., Vinoy, S. and Wieckert, M.O. (2016). Impact of Diet Composition on Blood Glucose. Critical Reviews in Food Science and Nutrition, 56(4), 564-565. https:// doi.org/10.1080/10408398.2013.792772
Saeed, M., Yasmin, I., Pasha, I., Randhawa, M.A. and Khan, M.I. (2015). Potential Application of Inulin in Food Industry; A review. Pakistan Society Of Food Scientists And Technology, 25(3), 110-116.

Stevenson, D.G., Jane, J.L. and Inglett, G.E. (2007). Characterisation of jícama (Mexican potato) (Pachyrhizus erosus L. Urban) starch from Taproots grown in USA and Mexico. Starch/Staerke, 59(3-4), 132-140. https://doi.org/10.1002/star.200600596

Stroud, M., Duncan, H. and Nightingale, J. (2003). Guidelines for Enteral Feeding in Adult Hospital Patients. Gut, 52(7), 81-82. https://doi.org/10.1136/ gut.52.suppl_7.vii1

Sun, J. and Zhai, W. (2012). Effect of Particle Size on Solubility, Dissolution Rate, and Oral Bioavailability : Evaluation using Coenzyme Q 10 as Naked Nanocrystals. International Journal of Nanomedicine, 7, 5733-5744. https:// doi.org/10.2147/IJN.S34365

Tamanna, N. and Mahmood, N. (2015). Food Processing and Maillard Reaction Products: Effect on Human Health and Nutrition. International Journal of Food Science, 2015, $526762 \quad$ https:// doi.org/10.1155/2015/526762

Vara-ubol, S., Ivz, E.C., Chambers, D.H. and Hall, J. (2003). Sensory Characteristics of Chemical Compounds Potentially Associated with Beany Aroma in Food. Journal of Sensory Studies, 19(785), $15-26$ https://doi.org/10.1111/j.1745459X.2004.tb00133.x

Venn, B. and Green, T.J. (2007). Glycemic index and glycemic load: measurement issues and their effect on diet-disease relationships. European Journal of Clinical Nutrition, 61, 122-131. https:// doi.org/10.1038/sj.ejen.1602942

Whelan, W.J., Hollar, D., Agatston, A., Dodson, H J. and Tahal, D.S. (2010). The Glycemic Response is a Personal Attribute. IUBMB Life, 62(8), 637-641. https://doi.org/10.1002/iub.365

$\mathrm{Wu}$, P.-H., Wu, Mi.-C. and Yu-Kuoe, C. (2017). Regulation Effect of Tempeh (tempeh) in Serum Glucose in Type II Diabetic Rats. Journal of Nutrition Food Science, 7, 4.

Yulianti, L. and Sholichah, E. (2019). Addition of Tempeh Flour as a Protein Source in Mixed Flour (Mocaf, Rice, and Corn) for Pasta Product. IOP Conference Series Earth and Environmental Science, $251, \quad 012037 . \quad$ https://doi.org/10.1088/1755$1315 / 251 / 1 / 012037$ 